\title{
Effect of remote ischemic conditioning on atrial fibrillation and outcome after coronary artery bypass grafting (RICO-trial)
}

Daniel Brevoord', Markus W Hollmann', Stefan G De Hert', Eric HPA van Dongen², Bram GADH Heijnen², Anton de Bruin², Noortje Tolenaar ${ }^{2}$, Wolfgang S Schlack', Nina C Weber ${ }^{1}$, Marcel GW Dijkgraaf ${ }^{3}$, Joris R de Groot ${ }^{4}$, Bas AJM de $\mathrm{Mol}^{5}$, Antoine HG Driessen ${ }^{5}$, Mona Momeni ${ }^{6}$, Patrick Wouters ${ }^{7}$, Stefaan Bouchez ${ }^{7}$, Jan Hofland ${ }^{8}$, Christan Lüthen ${ }^{8}$, Tanja A Meijer-Treschan ${ }^{9}$, Benedikt $\mathrm{H} \mathrm{Pannen}^{9}$ and Benedikt Preckel ${ }^{{ }^{*}}$

\begin{abstract}
Background: Pre- and postconditioning describe mechanisms whereby short ischemic periods protect an organ against a longer period of ischemia. Interestingly, short ischemic periods of a limb, in itself harmless, may increase the ischemia tolerance of remote organs, e.g. the heart (remote conditioning, RC). Although several studies have shown reduced biomarker release by RC, a reduction of complications and improvement of patient outcome still has to be demonstrated. Atrial fibrillation (AF) is one of the most common complications after coronary artery bypass graft surgery $(C A B G)$, affecting $27-46 \%$ of patients. It is associated with increased mortality, adverse cardiovascular events, and prolonged in-hospital stay. We hypothesize that remote ischemic pre- and/or postconditioning reduce the incidence of AF following CABG, and improve patient outcome.
\end{abstract}

Methods/design: This study is a randomized, controlled, patient and investigator blinded multicenter trial. Elective CABG patients are randomized to one of the following four groups: 1) control, 2) remote ischemic preconditioning, 3) remote ischemic postconditioning, or 4) remote ischemic pre- and postconditioning. Remote conditioning is applied at the arm by 3 cycles of 5 minutes of ischemia and reperfusion. Primary endpoint is the incidence AF in the first 72 hours after surgery, detected using a Holter-monitor. Secondary endpoints include length-of-stay on the intensive care unit and in-hospital, and the occurrence of major adverse cardiovascular events at 30 days, 3 months and 1 year.

Based on an expected incidence in the control group of 27\%, 195 patients per group are needed to detect with $80 \%$ power a reduction by $45 \%$ following either pre- or postconditioning, while allowing for a $10 \%$ dropout and at an alpha of 0.05 . With the combined intervention expected to be stronger, we need 75 patients in this group to detect a reduction in incidence of AF of $60 \%$.

Discussion: The RICO-trial (the effect of Remote Ischemic Conditioning on atrial fibrillation and Outcome) is a randomized controlled multicenter trial, designed to investigate whether remote ischemic pre- and/or postconditioning of the arm reduce the incidence of AF following CABG surgery.

Trial registration: ClinicalTrials.gov under NCT01107184.

\footnotetext{
* Correspondence: b.preckel@amc.uva.nl

'Department of Anaesthesiology, Laboratory of Experimental Intensive Care and Anaesthesiology (L.E.I.C.A.), Academic Medical Centre Amsterdam, The Netherlands

Full list of author information is available at the end of the article
}

\section{Biomed Central}

(c) 2011 Brevoord et al; licensee BioMed Central Ltd. This is an Open Access article distributed under the terms of the Creative Commons Attribution License (http://creativecommons.org/licenses/by/2.0), which permits unrestricted use, distribution, and reproduction in any medium, provided the original work is properly cited. 


\section{Background}

It has been demonstrated previously that an organ can develop tolerance against ischemic stress by different interventions. In experimental studies, short periods (e. g., 3-5 minutes) of myocardial ischemia before the sustained ischemic period significantly reduced infarct size (early and late preconditioning) [1-3]. In addition, there is a significant amount of tissue that is damaged during early reperfusion, and it has been shown that staged reperfusion or short periods of ischemia (seconds to minutes) at the start of reperfusion, limits tissue damage (postconditioning) [4-6].

Besides periods of ischemia, several drugs may also induce this organ tolerance by pre- and postconditioning. These include nitrates, $[7,8]$ opioids, $[9,10]$ volatile anaesthetics [11-13] and noble gases [14,15]. While the application of short periods of organ ischemia is quite invasive and in most clinical settings not feasible, the named drugs mostly have significant hemodynamic or neurologic (anaesthetic) side effects preventing their use in a broad patient population (also outside the operating theatre).

Recently, a fascinating possibility to protect tissue against ischemia-reperfusion damage has been described. Remote ischemic pre- and postconditioning refer to the protective effect on the heart that can be induced by submitting another organ or skeletal muscle to multiple short periods of ischemia and reperfusion. Studies in animals have shown a reduction in infarct size after short periods of preconditioning ischemia (RIPC) on a remote organ $[16,17]$. In addition, clamping and releasing the femoral or renal artery before the onset of reperfusion can reduce myocardial infarct size (remote postconditioning, RpostC); [18] multiple cycles of ischemia reperfusion applied to the hind limb during myocardial reperfusion reduced infarct size in rabbits and pigs $[19,20]$.

In humans, RIPC by short-term non-invasive limb ischemia reduced troponin I release after elective percutaneous coronary intervention (PCI) [21]. In patients subjected to coronary artery bypass graft (CABG) surgery, RIPC reduced myocardial damage as measured by biomarker release $[22,23]$. RpostC at the onset of reperfusion protected human endothelium against ischemia reperfusion injury [24]. Recently, this was translated to patients with acute myocardial infarction: applying short periods of forearm ischemia-reperfusion in patients with acute coronary syndrome by ambulance personal during transport to the hospital reduced infarct size as measured by cardiac perfusion scintigraphy [25].

Until today it is not known whether the reduction in tissue damage and reduced biomarker release will translate into better outcome of these patients. If an easily applicable procedure like remote conditioning leads to improved outcome in patients with planned or acute ischemic periods, such an intervention would be of great help in patient care. Hoole et al. demonstrated a reduction of major adverse cardiac events (MACE) after RIPC in patients undergoing elective PCI [21]. The role of RIPC and RpostC in the reduction of perioperative arrhythmias is unknown. Therefore, the present study investigates for the first time the long-time effects of $\mathrm{RIPC}, \mathrm{RpostC}$, and the combination of both procedures, in patients subjected to CABG surgery.

Atrial fibrillation (AF) is one of the most common complications after CABG surgery, affecting $27-46 \%$ of patients. It is associated with increased mortality, adverse cardiovascular events, and prolonged in-hospital stay. We hypothesize that RIPC and/or RpostC reduce the incidence of $\mathrm{AF}$ following $\mathrm{CABG}$, and improve patient outcome.

\section{Methods/design \\ Study objectives}

The objective of this study is to investigate whether the safe and simple intervention of remote ischemic conditioning, (pre-, post-conditioning, or both), improves clinical outcome after CABG surgery, as measured by the incidence of postoperative atrial fibrillation, the length of stay on the intensive care unit (ICU) and inhospital length of stay, and the occurrence of MACE at follow up.

\section{Study design}

The RICO-trial is a randomized controlled multi-centre trial, utilizing four parallel arms. Patients are blinded for the treatment allocation since the study intervention will be done under general anaesthesia. In addition, investigators analyzing the data will be blinded and statistical analysis will be done using coded treatment groups, which will only be revealed after the analysis. However, local investigators responsible for inclusion of patients and executing the study protocol, will not be blinded

Patients scheduled for an elective, isolated CABG procedure, will be eligible. After inclusion, subjects will be randomized to one of the following arms 1) control, 2) remote ischemic preconditioning (RIPC), 3) remote ischemic postconditioning (RpostC), or 4) remote ischemic pre- and postconditioning (RIPC+RpostC). Randomization will be done using an internet based randomization application, with a biased coin approach and stratified for participating centre.

\section{Ethics}

The study will be conducted in accordance with the principles of the Declaration of Helsinki, the Medical Research Involving Human Subjects Act (WMO) and the principles of "good clinical practice". The independent medical ethics committee of the Academic Medical 
Center in Amsterdam has approved the study for the hospitals in the Netherlands (approval number 09.017.1769, trial number MEC09/186), and the independent medical ethics committees of the centres in Belgium and Germany for these respective centres. Written informed consent is obtained from all participating patients.

The study is registered at ClinicalTrials.gov under NCT01107184.

\section{Participating centres}

Patients will be enrolled in at least six centres; two academic centres and one non-academic centre in the Netherlands, two academic centres in Belgium and one academic centre in Germany.

\section{Study population}

The study population consists of patients scheduled for elective CABG surgery in one of the participating centres.

Inclusion criteria are: elective CABG without valve surgery, the use of extra corporeal circulation, $>18$ years of age.

Exclusion criteria are: prior cardiac surgery, a history of AF, use of a class 1 or 3 anti arrhythmic drug or digoxin, intermittent aortic cross clamping during surgery, left ventricular ejection fraction $\leq 30 \%$, serious pulmonary disease, renal failure, liver failure and the use of glibenclamide.

\section{Study outline}

Local researchers will recruit and randomize patients, perform the study intervention, collect baseline, perioperative and follow-up data and take care of the Holter-monitoring. Depending on the centre, patients will be screened and asked for consent either during the outpatient screening or while hospitalized prior to surgery. Randomization will be done after inclusion and prior to surgery.

All patients will have a surgical tourniquet placed on the upper arm prior to surgery. These tourniquets, which are also used in orthopaedic surgery to create a bloodless operating field, use compressed air and can create and maintain a preset pressure. Patients in the RIPC group and in the RIPC+RpostC group will have their tourniquet inflated to $200 \mathrm{mmHg}$ for $3 \times 5 \mathrm{~min}$ utes after the induction of anaesthesia but before the start of cardiopulmonary bypass. During aortic crossclamp, patients in both the RpostC group and the RIPC + RpostC group will have their tourniquet inflated for 3 $\times 5$ minutes. In the control group, no tourniquet inflating will be done. Peripheral saturation and invasive blood pressure monitoring will be done using the contra-lateral arm, so that ischemic conditioning will not hinder monitoring. Anaesthesia

Anaesthesia will be performed according to good clinical standard procedures. Patients will be pre-medicated with midazolam $7.5 \mathrm{mg}$ p.o. Induction of anaesthesia will be with intravenously (i.v.) applied midazolam 0,1$0,2 \mathrm{mg} / \mathrm{kg}$ and/or propofol TCI, i.v. sufentanil 1,0-1,5 $\mu \mathrm{g} / \mathrm{kg}$ and i.v. rocuronium $0,6 \mathrm{mg} / \mathrm{kg}$. Continuous infusion of sufentanil $(0,3 \mu \mathrm{g} / \mathrm{kg} / \mathrm{h})$ and propofol TCI will be used for maintenance of anaesthesia; anaesthesia depth will not be monitored routinely.

\section{Surgery}

Surgical procedures include the use of extra corporal circulation but are otherwise not standardized, except for the exclusion of intermitted aortic cross clamping. Peri-operative care will be provided according to local standards.

\section{Arrhythmias}

In case AF develops, the patient should be treated according to local protocol, which may include either sotalol or amiodarone, but is not restricted to these medications. There will be no use of prophylactic medication for AF (e.g. prophylactic sotalol or amiodarone).

\section{Postoperatively}

At the end of surgery, prior to transportation to the intensive care unit, a Holter-monitor (Spacelabs Lifecard CF ECG) will be attached to the participants for monitoring of postoperative AF. After transportation to the ICU the monitor will be checked for proper attachment and thereafter once a day. After 72 hours the monitors will be collected and the data downloaded.

\section{Follow-up}

After discharge from the hospital, the patients will be contacted at 30 days, 3 months and 1 year after the initial surgery by phone and requested to fill out a mailed questionnaire. In addition, patients' physicians will be contacted after 1 year to complete the record. They will be questioned about the occurrence of rhythm disturbances, heart failure, revascularisation, acute coronary syndrome, myocardial infarction and transient ischemic attacks and stroke.

\section{Data collection and monitoring}

Data of each patient will be noted in an individual case report form (CRF), identifiable by a study-specific patient identification number. CRF's will be stored locally and send electronically to the AMC. Holter data will be downloaded from the devices and transported or send to the AMC for central analysis and storage. Questionnaires will be mailed to the participants 30 days, 3 months and 1 year after surgery.

There will be regular meetings between the study coordinators and the main investigators of each site. 


\section{Data analysis}

Holter data analysis will be done using Spacelabs Pathfinder Software Kit (version 9.019) and under supervision of a cardiologist of the Academic Medical Centre Amsterdam, The Netherlands.

\section{Endpoints}

\section{Primary endpoint}

The primary endpoint is the percentage of patients that develop AF during the first 72 hours postoperatively.

\section{Secondary endpoint}

Secondary endpoints include the percentage of patients with AF on each post-operative day, the total duration of AF and the number of episodes, the length of stay on the ICU as well as the in hospital stay and the MACE rate at 30 days, 3 months and 1 year follow-up.

\section{Statistical analysis Sample size calculation}

We hypothesize that pre- or post-conditioning will decrease the probability of AF by 40 to 50 per cent at a background rate of 27 per 100 CABG patients treated, which might be a clinically relevant reduction of AF. The effort of a combination of pre- and post-conditioning may only be relevant if there is additional reduction of AF, meaning that the combination is even more effective and might reduce the occurrence of AF by another $15 \%$. In case of the pre- or post-conditioning groups a reduction in proportion AF from 0.27 to 0.1485 (minus $45 \%)$ seems feasible and clinically relevant. In case of the pre- and post-conditioning group a gain of at least $60 \%$, from 0.27 to 0.108 (minus $60 \%$ ), is considered clinically relevant. Sample sizes of 175 patients in the control group and 175 patients in the pre-conditioning group achieve $80 \%$ power to detect a difference between the group proportions of -0.1215 . The test used is the two-group $\mathrm{Chi}^{2}$-test with a two-sided 0.05 significance level. Similarly, the number of patients sampled for the post-conditioning group should also be 175 . With 175 patients in the control group, the number of patients needed in the pre- and post-conditioning group should be at least 66 to achieve $80 \%$ power to detect a difference between the group proportions of -0.162 , using, again, a two-group $\mathrm{Chi}^{2}$-test with a two-sided 0.05 significance level. To account for $10 \%$ possible drop-out of patients 195 patients are needed in the control group, the pre-conditioning group, and the post-conditioning group respectively, while 75 patients are needed in the pre- and post-conditioning group. In total, 660 patients are needed.

\section{Discussion}

Recently, remote ischemic conditioning gained attention as a possibility to protect different organs against ischemia reperfusion injury. Due to the safe and noninvasive nature of the intervention, this protection might be applicable in numerous patients. Small studies in cardiac surgery using biomarker release as endpoint suggest a beneficial effect of remote conditioning, [22,23,26-29] although not all studies are positive [30]. Although biomarker release following cardiac surgery is an accepted surrogate outcome parameter, [31-33] there is no evidence that remote conditioning leads to an improved outcome. Therefore, routinely use of remote conditioning cannot be recommended at this time. A study investigating the effects of remote ischemic conditioning on outcome parameters such as survival or quality of life would require a huge number of patients. We choose post-operative AF as a surrogate endpoint in this study, since it is not only a predictor of outcome, but prevention of AF also improves outcome [34-39]. The aetiology of AF following cardiac surgery is multi-factorial and not fully elucidated; however, ischemia reperfusion injury sustained during clamping of the aorta and generation of radical oxygen species during reperfusion play an important role. Ischemic conditioning is known to improve these processes. Indeed, direct ischemic conditioning has been shown to reduce post-operative arrhythmias [40-43]. Therefore, we hypothesize that remote ischemic conditioning can reduce AF.

Most ischemic periods (e.g., acute coronary syndrome, stroke) are unpredictable, and therefore RIPC is not feasible. A protective measure that can be applied after the onset of ischemia, such as RpostC, might have greater clinical implications. We therefore choose to include next to RIPC also RpostC, which has been demonstrated to be effective in animal and volunteer studies and a small trial in patients $[18-20,24,44,45]$. There is evidence that in aged or diseased myocardium, the ability to induce conditioning is reduced [46-48,46,47,49]. Therefore, we speculate that the added effect of both pre- and postconditioning could provide an additive protection not achieved by either intervention alone. Since such an effect should be more powerful to justify the extra effort, we expect an increased reduction in AF in the pre- and postconditioning group and will therefore include a smaller number of patients in this group.

In conclusion, the RICO-trial is a randomized controlled multicenter trial to investigate whether remote ischemic conditioning (RIPC, RpostC, or both) can reduce complications and improve outcome after CABG surgery.

\section{Author details}

${ }^{1}$ Department of Anaesthesiology, Laboratory of Experimental Intensive Care and Anaesthesiology (L.E.I.C.A.), Academic Medical Centre Amsterdam, The Netherlands. ${ }^{2}$ Department of Anaesthesiology, St. Antonius Ziekenhuis, Nieuwegein, The Netherlands. ${ }^{3}$ Clinical Research Unit, Academic Medical 
Centre Amsterdam, The Netherlands. ${ }^{4}$ Department of Cardiology, Academic Medical Centre Amsterdam, The Netherlands. ${ }^{5}$ Department of Cardiothoracic Surgery, Academic Medical Centre Amsterdam, The Netherlands. ${ }^{6}$ Department of Anaesthesiology, UCL Brussels, Belgium. ${ }^{7}$ Department of Anaesthesiology, UZ Gent, Belgium. ${ }^{8}$ Department of Anaesthesiology, Erasmus Medical Centre Rotterdam, The Netherlands. ${ }^{9}$ Department of Anaesthesiology and Intensive Care, University Hospital Düsseldorf, Germany.

\section{Authors' contributions}

DB drafted the manuscript and BP co-authored the writing. MGWD provided statistical and methodological advice, JR de G will supervise the Holtermonitor data analysis. All other authors participated in the design of the study during several meetings and/or are local investigators in the participating centres. All authors have read and approved the final manuscript

\section{Competing interests}

The authors declare that they have no competing interests.

Received: 6 January 2011 Accepted: 23 May 2011

Published: 23 May 2011

\section{References}

1. Murry CE, Jennings RB, Reimer KA: Preconditioning with ischemia: a delay of lethal cell injury in ischemic myocardium. Circulation 1986, 74(5):1124-1136.

2. Marber MS, Latchman DS, Walker JM, Yellon DM: Cardiac stress protein elevation 24 hours after brief ischemia or heat stress is associated with resistance to myocardial infarction. Circulation 1993, 88(3):1264-1272.

3. Kuzuya T, Hoshida S, Yamashita N, Fuji H, Oe H, Hori M, Kamada T, Tada M: Delayed effects of sublethal ischemia on the acquisition of tolerance to ischemia. Circ Res 1993, 72(6):1293-1299.

4. Zhao ZQ, Corvera JS, Halkos ME, Kerendi F, Wang NP, Guyton RA, VintenJohansen J: Inhibition of myocardial injury by ischemic postconditioning during reperfusion: comparison with ischemic preconditioning. Am J Physiol Heart Circ Physiol 2003, 285(2):H579-H588.

5. Staat P, Rioufol G, Piot C, Cottin Y, Cung TT, L'Huillier I, Aupetit JF, Bonnefoy E, Finet G, André-Fouët $X$, Ovize M: Postconditioning the human heart. Circulation 2005, 112(14):2143-2148.

6. Laskey WK: Brief repetitive balloon occlusions enhance reperfusion during percutaneous coronary intervention for acute myocardial infarction: a pilot study. Catheter Cardiovasc Interv 2005, 65(3):361-367.

7. Lamping KA, Christensen CW, Pelc LR, Warltier DC, Gross GJ: Effects of nicorandil and nifedipine on protection of ischemic myocardium. J Cardiovasc Pharmacol 1984, 6(3):536-542.

8. Matsubara T, Minatoguchi S, Matsuo H, Hayakawa K, Segawa T, Matsuno $Y$, Watanabe S, Arai M, Uno Y, Kawasaki M, Noda T, Takemura G, Nishigaki K, Fujiwara $\mathrm{H}$ : Three minute, but not one minute, ischemia and nicorandil have a preconditioning effect in patients with coronary artery disease. J Am Coll Cardiol 2000, 35(2):345-351.

9. McPherson $B C$, Yao Z: Morphine mimics preconditioning via free radical signals and mitochondrial K(ATP) channels in myocytes. Circulation 2001, 103(2):290-295.

10. Frässdorf J, Weber NC, Obal D, Toma O, Müllenheim J, Kojda G, Preckel B, Schlack W: Morphine induces late cardioprotection in rat hearts in vivo: the involvement of opioid receptors and nuclear transcription factor kappaB. Anesth Analg 2005, 101(4):934-41, table of contents.

11. Cope DK, Impastato WK, Cohen MV, Downey JM: Volatile anesthetics protect the ischemic rabbit myocardium from infarction. Anesthesiology 1997, 86(3):699-709.

12. Kersten JR, Schmeling TJ, Pagel PS, Gross GJ, Warltier DC: Isoflurane mimics ischemic preconditioning via activation of K(ATP) channels: reduction of myocardial infarct size with an acute memory phase. Anesthesiology 1997, 87(2):361-370.

13. Preckel B, Schlack W, Comfère T, Obal D, Barthel H, Thämer V: Effects of enflurane, isoflurane, sevoflurane and desflurane on reperfusion injury after regional myocardial ischaemia in the rabbit heart in vivo. $\mathrm{Br} J$ Anaesth 1998, 81(6):905-912.

14. Weber NC, Toma O, Wolter JI, Obal D, Müllenheim J, Preckel B, Schlack W: The noble gas xenon induces pharmacological preconditioning in the rat heart in vivo via induction of PKC-epsilon and p38 MAPK. Br J Pharmacol 2005, 144(1):123-132.

15. Pagel PS, Krolikowski JG, Shim YH, Venkatapuram S, Kersten JR, Weihrauch D, Warltier DC, Pratt PF: Noble gases without anesthetic properties protect myocardium against infarction by activating prosurvival signaling kinases and inhibiting mitochondrial permeability transition in vivo. Anesth Analg 2007, 105(3):562-569.

16. Przyklenk K, Bauer B, Ovize M, Kloner RA, Whittaker P: Regional ischemic 'preconditioning' protects remote virgin myocardium from subsequent sustained coronary occlusion. Circulation 1993, 87(3):893-899.

17. Kharbanda RK, Mortensen UM, White PA, Kristiansen SB, Schmidt MR, Hoschtitzky JA, Vogel M, Sorensen K, Redington AN, MacAllister R: Transient limb ischemia induces remote ischemic preconditioning in vivo. Circulation 2002, 106(23):2881-2883.

18. Kerendi F, Kin H, Halkos ME, Jiang R, Zatta AJ, Zhao ZQ, Guyton RA, VintenJohansen J: Remote postconditioning. Brief renal ischemia and reperfusion applied before coronary artery reperfusion reduces myocardial infarct size via endogenous activation of adenosine receptors. Basic Res Cardiol 2005, 100(5):404-412.

19. Li CM, Zhang XH, Ma XJ, Luo M: Limb ischemic postconditioning protects myocardium from ischemia-reperfusion injury. Scand Cardiovasc J 2006, 40(5):312-317.

20. Andreka G, Vertesaljai M, Szantho G, Font G, Piroth Z, Fontos G, Juhasz ED, Szekely L, Szelid Z, Turner MS, Ashrafian H, Frenneaux MP, Andreka P: Remote ischaemic postconditioning protects the heart during acute myocardial infarction in pigs. Heart 2007, 93(6):749-752.

21. Hoole SP, Heck PM, Sharples L, Khan SN, Duehmke R, Densem CG, Clarke SC, Shapiro LM, Schofield PM, O'Sullivan M, Dutka DP: Cardiac Remote Ischemic Preconditioning in Coronary Stenting (CRISP Stent) Study: a prospective, randomized control trial. Circulation 2009, 119(6):820-827.

22. Hausenloy DJ, Mwamure PK, Venugopal V, Harris J, Barnard M, Grundy E, Ashley E, Vichare S, Di Salvo C, Kolvekar S, Hayward M, Keogh B, MacAllister RJ, Yellon DM: Effect of remote ischaemic preconditioning on myocardial injury in patients undergoing coronary artery bypass graft surgery: a randomised controlled trial. Lancet 2007, 370(9587):575-579.

23. Venugopal V, Hausenloy DJ, Ludman A, Di Salvo C, Kolvekar S, Yap J, Lawrence D, Bognolo J, Yellon DM: Remote ischaemic preconditioning reduces myocardial injury in patients undergoing cardiac surgery with cold-blood cardioplegia: a randomised controlled trial. Heart 2009, 95(19):1567-1571.

24. Loukogeorgakis SP, Williams R, Panagiotidou AT, Kolvekar SK, Donald A, Cole TJ, Yellon DM, Deanfield JE, MacAllister RJ: Transient limb ischemia induces remote preconditioning and remote postconditioning in humans by a K(ATP)-channel dependent mechanism. Circulation 2007, 116(12):1386-1395

25. Bøtker HE, Kharbanda R, Schmidt MR, Bøttcher M, Kaltoft AK, Terkelsen CJ, Munk K, Andersen NH, Hansen TM, Trautner S, Lassen JF, Christiansen EH, Krusell LR, Kristensen SD, Thuesen L, Nielsen SS, Rehling M, Sørensen HT, Redington AN, Nielsen TT: Remote ischaemic conditioning before hospital admission, as a complement to angioplasty, and effect on myocardial salvage in patients with acute myocardial infarction: a randomised trial. Lancet 2010, 375(9716):727-734.

26. Cheung MMH, Kharbanda RK, Konstantinov IE, Shimizu M, Frndova H, Li J, Holtby HM, Cox PN, Smallhorn JF, Van Arsdell GS, Redington AN: Randomized controlled trial of the effects of remote ischemic preconditioning on children undergoing cardiac surgery: first clinical application in humans. J Am Coll Cardiol 2006, 47(11):2277-2282.

27. Ali ZA, Callaghan CJ, Lim E, Ali AA, Nouraei SAR, Akthar AM, Boyle JR, Varty K, Kharbanda RK, Dutka DP, Gaunt ME: Remote ischemic preconditioning reduces myocardial and renal injury after elective abdominal aortic aneurysm repair: a randomized controlled trial. Circulation 2007, 116(11 Suppl):198-105.

28. Thielmann M, Kottenberg E, Boengler K, Raffelsieper C, Neuhaeuser M, Peters J, Jakob H, Heusch G: Remote ischemic preconditioning reduces myocardial injury after coronary artery bypass surgery with crystalloid cardioplegic arrest. Basic Res Cardiol 2010, 105(5):657-664.

29. Zhou W, Zeng D, Chen R, Liu J, Yang G, Liu P, Zhou X: Limb ischemic preconditioning reduces heart and lung injury after an open heart operation in infants. Pediatr Cardiol 2010, 31(1):22-29. 
30. Rahman IA, Mascaro JG, Steeds RP, Frenneaux MP, Nightingale P, Gosling P, Townsend P, Townend JN, Green D, Bonser RS: Remote ischemic preconditioning in human coronary artery bypass surgery: from promise to disappointment? Circulation 2010, 122(11 Suppl):S53-S59.

31. Greenson N, Macoviak J, Krishnaswamy P, Morrisey R, James C, Clopton P, Fitzgerald R, Maisel AS: Usefulness of cardiac troponin I in patients undergoing open heart surgery. Am Heart J 2001, 141(3):447-455.

32. Fellahi JL, Gué X, Richomme X, Monier E, Guillou L, Riou B: Short- and long-term prognostic value of postoperative cardiac troponin I concentration in patients undergoing coronary artery bypass grafting. Anesthesiology 2003, 99(2):270-274.

33. Lehrke $S$, Steen $H$, Sievers HH, Peters H, Opitz A, Müller-Bardorff M, Wiegand UKH, Katus HA, Giannitsis E: Cardiac troponin T for prediction of short- and long-term morbidity and mortality after elective open heart surgery. Clin Chem 2004, 50(9):1560-1567.

34. Almassi GH, Schowalter T, Nicolosi AC, Aggarwal A, Moritz TE, Henderson WG, Tarazi R, Shroyer AL, Sethi GK, Grover FL, Hammermeister KE: Atrial fibrillation after cardiac surgery: a major morbid event? Ann Surg 1997, 226(4):501-11, discussion 511.

35. Maisel WH, Rawn JD, Stevenson WG: Atrial fibrillation after cardiac surgery. Ann Intern Med 2001, 135(12):1061-1073.

36. Crystal E, Garfinkle MS, Connolly SS, Ginger TT, Sleik K, Yusuf SS: Interventions for preventing post-operative atrial fibrillation in patients undergoing heart surgery. Cochrane Database Syst Rev 2004, , 4: CD003611.

37. Villareal RP, Hariharan R, Liu BC, Kar B, Lee W, Elayda M, Lopez JA, Rasekh A, Wilson JM, Massumi A: Postoperative atrial fibrillation and mortality after coronary artery bypass surgery. J Am Coll Cardiol 2004, 43(5):742-748.

38. Mathew JP, Fontes ML, Tudor IC, Ramsay J, Duke P, Mazer CD, Barash PG, Hsu PH, Mangano DT, Investigators of the Ischemia Research and Education Foundation, Multicenter Study of Perioperative Ischemia Research Group: A multicenter risk index for atrial fibrillation after cardiac surgery. JAMA 2004, 291(14):1720-1729.

39. Mariscalco G, Klersy C, Zanobini M, Banach M, Ferrarese S, Borsani P, Cantore C, Biglioli P, Sala A: Atrial fibrillation after isolated coronary surgery affects late survival. Circulation 2008, 118(16):1612-1618.

40. Laurikka J, Wu ZK, lisalo P, Kaukinen L, Honkonen EL, Kaukinen S, Tarkka MR: Regional ischemic preconditioning enhances myocardial performance in off-pump coronary artery bypass grafting. Chest 2002, 121(4):1183-1189.

41. Wu ZK, livainen T, Pehkonen E, Laurikka J, Tarkka MR: Perioperative and postoperative arrhythmia in three-vessel coronary artery disease patients and antiarrhythmic effects of ischemic preconditioning. Eur $\mathrm{J}$ Cardiothorac Surg 2003, 23(4):578-584

42. Wu ZK, livainen T, Pehkonen E, Laurikka J, Tarkka MR: Arrhythmias in offpump coronary artery bypass grafting and the antiarrhythmic effect of regional ischemic preconditioning. J Cardiothorac Vasc Anesth 2003, 17(4):459-464.

43. Wu ZK, livainen T, Pehkonen E, Laurikka J, Tarkka MR: Antiarrhythmic effect of ischemic preconditioning in recent unstable angina patients undergoing coronary artery bypass grafting. World J Surg 2004, 28(1):74-79.

44. Kharbanda RK, Li J, Konstantinov IE, Cheung MMH, White PA, Frndova H, Stokoe J, Cox P, Vogel M, Van Arsdell G, MacAllister R, Redington AN: Remote ischaemic preconditioning protects against cardiopulmonary bypass-induced tissue injury: a preclinical study. Heart 2006, 92(10):1506-1511.

45. Li L, Luo W, Huang L, Zhang W, Gao Y, Jiang H, Zhang C, Long L, Chen S: Remote perconditioning reduces myocardial injury in adult valve replacement: a randomized controlled trial. J Surg Res 2010, 164(1): e21-e26.

46. Abete P, Ferrara N, Cacciatore F, Madrid A, Bianco S, Calabrese C, Napoli C, Scognamiglio P, Bollella O, Cioppa A, Longobardi G, Rengo F: Anginainduced protection against myocardial infarction in adult and elderly patients: a loss of preconditioning mechanism in the aging heart? J Am Coll Cardiol 1997, 30(4):947-954.

47. Ghosh S, Standen NB, Galiñianes M: Failure to precondition pathological human myocardium. J Am Coll Cardiol 2001, 37(3):711-718.

48. Huhn R, Heinen A, Weber NC, Kerindongo RP, Oei GTML, Hollmann MW Schlack W, Preckel B: Helium-induced early preconditioning and postconditioning are abolished in obese Zucker rats in vivo. J Pharmacol Exp Ther 2009, 329(2):600-607.
49. Heinen A, Huhn R, Smeele KMA, Zuurbier CJ, Schlack W, Preckel B, Weber NC, Hollmann MW: Helium-induced preconditioning in young and old rat heart: impact of mitochondrial $\mathrm{Ca}(2+)$-sensitive potassium channel activation. Anesthesiology 2008, 109(5):830-836.

\section{Pre-publication history}

The pre-publication history for this paper can be accessed here: http://www.biomedcentral.com/1471-2253/11/11/prepub

doi:10.1186/1471-2253-11-11

Cite this article as: Brevoord et al:: Effect of remote ischemic conditioning on atrial fibrillation and outcome after coronary artery bypass grafting (RICO-trial). BMC Anesthesiology 2011 11:11.

\section{Submit your next manuscript to BioMed Central and take full advantage of:}

- Convenient online submission

- Thorough peer review

- No space constraints or color figure charges

- Immediate publication on acceptance

- Inclusion in PubMed, CAS, Scopus and Google Scholar

- Research which is freely available for redistribution

Submit your manuscript at www.biomedcentral.com/submit
C Biomed Central 